\title{
Evolving from a traditional distance learning model to e-learning
}

\author{
Michalis Xenos, Athanassios Skodras \\ Hellenic Open University, School of Sciences \& Technology \\ GR 26222, Patras, Greece \\ Tel. +30 2610361485 , Fax: +30 2610361349 , \\ \{xenos, skodras\}@eap.gr
}

\begin{abstract}
This paper presents experiences from the course of Informatics at the Hellenic Open University. Problems faced and lessons learned are presented relating to the introduction of e-learning capabilities into this course that was initially based on a traditional distance-learning model. The paper discusses the need that imposed the introduction of e-learning infrastructure and procedures into the course, the steps taken and the students' attitude towards these changes. It also discusses points where the GRID infrastructure can aid in the educational procedure.
\end{abstract}

Keywords: Distance Learning, E-Learning, Virtual Classrooms

\section{INTRODUCTION TO THE HOU CASE}

The Hellenic Open University (HOU) started to offer bachelor courses in the year 2000, based on the distance-learning model. Initially, many of the learning procedures were influenced by the British Open University [1] model. This model is a traditional distance model with limited or no use at all of e-learning facilities. In the HOU students study their material -mainly printed textbooks- from distance. In addition, they have the option to attend a small number of face-toface counseling meetings. Currently, the HOU provides six bachelor degree courses among which the course of Informatics.

The course of Informatics is a 4-year course comprised of 12 modules leading to a Bachelor Diploma in Informatics. Each student may register in one up to three modules per year, each of them being equivalent to 3 or 4 conventional university-level lessons. After more than 3 years of planning, preparing the textbooks (specialized material suitable for distance learning) and instructing the tutors, the course was made available in the academic year 2000-2001 allowing for the registration of 510 students. Another 720 students registered in 2001 and 720 more in 2002. According to the initial design of this course, students attending each module of the course were to be divided randomly in small groups of approximately 30 students. A tutor would be responsible for communicating with and supporting the students of each group. Moreover, the students of each group could attend 4 face-to-face meetings for each module. All students had to deliver a number of written assignments so as to gain the right to participate in the final module exams.

This paper presents the experiences relating to this course and why the need for enhancement in communication and tutoring means arose. This need lead to changes in the course that shifted its philosophy from a traditional distance-learning model to a mixed-model incorporating a number of e-learning facilities.

\section{THE DEMAND FOR CHANGES}


A distance learning system must take into account the particularities of each course and the specific cultural and geographical characteristics of the country. Keeping this in mind, six major cities were selected as locations for the face-to-face meetings of the course of Informatics. These locations are shown in Figure 1.

TABLE 1: Students that could easily travel to the meeting

\begin{tabular}{|l|c|}
\hline City & Students' \% \\
\hline \hline Athens & $60 \%$ \\
\hline Thessaloniki & $18 \%$ \\
\hline Patra & $7 \%$ \\
\hline Iraklio & $4 \%$ \\
\hline Ioannina & $3 \%$ \\
\hline Xanthi & $3 \%$ \\
\hline
\end{tabular}

Based on the student registry data of the first three years, the percentage of the students that needed no more than 3 hours to reach the meeting location (by car or boat) is shown in Table 1.

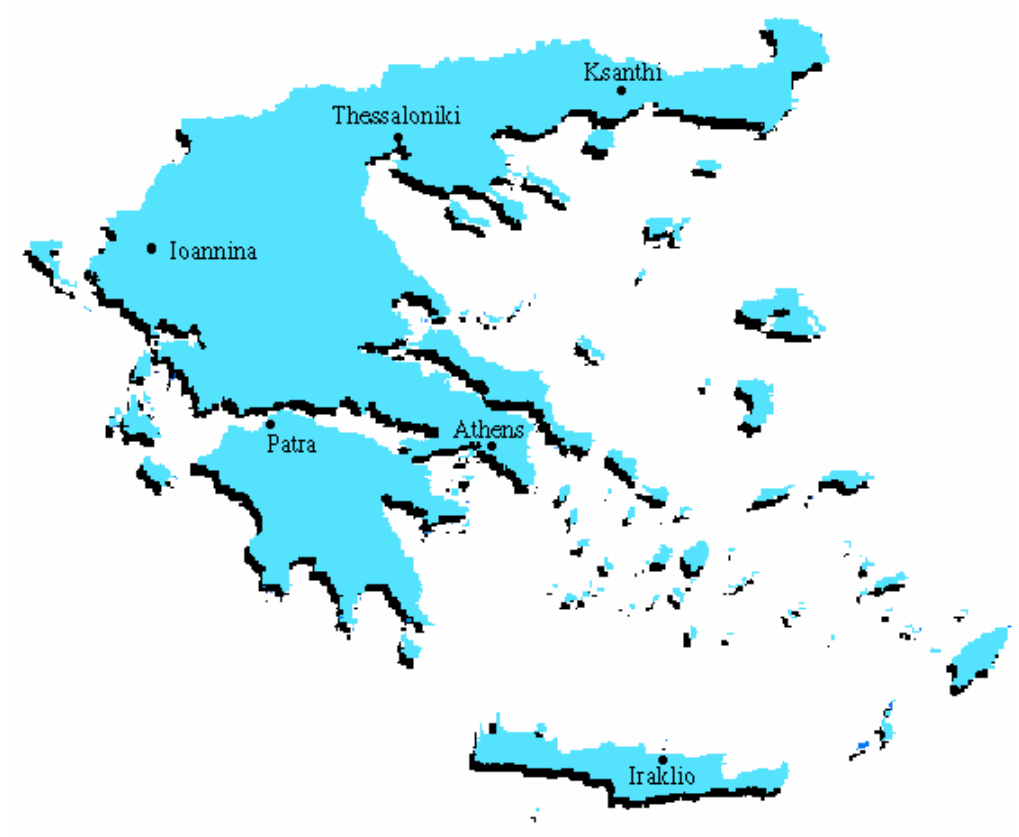

FIGURE 1: The 6 locations of face-to-face meetings

The distribution shown in Table 1 is typical for a country such as Greece where over half of the population lives in or near the capital. Although the majority of students could easily reach the meeting locations, a small percentage (approximately 5\%) of the students could not be served by any of the meeting locations. Among them were, for instance, students who live in the Aegean islands where, in the winter, there is no frequent transportation; consequently, a student living in such remote areas needed to travel 2-3 days earlier to attend a meeting. On the other hand, the alternative of organizing a meeting in another location closer to all these students was excluded since, in most cases, traveling from an island to another one near it means traveling to Athens and then back to this island. Figure 2 illustrates the distribution of the 32 students living in the Aegean islands attending one of the first year modules. 


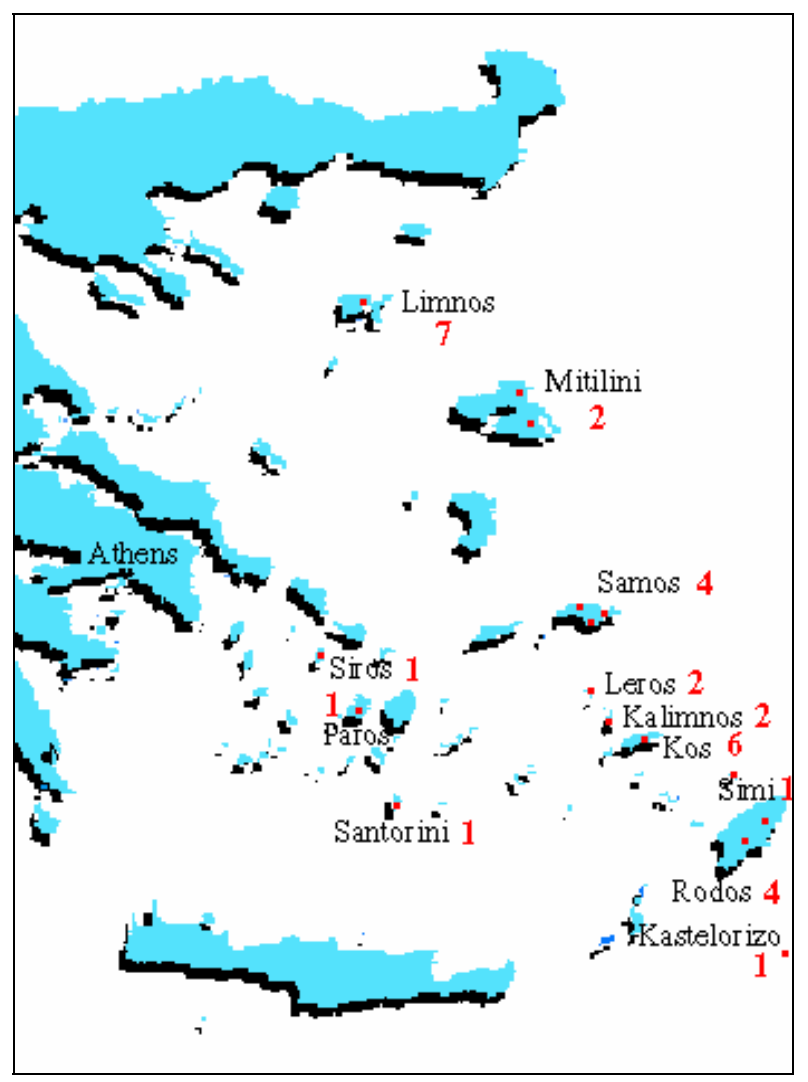

FIGURE 2: Students of the A14 group in the Aegean islands

The first year of the course indicated that 4 face-to-face meetings were not enough for the HOU students of this course, although this number appears to be enough for other distance-learning universities. This is supported by the fact that $78 \%$ of the students and $80 \%$ of the tutors asked for additional meetings or another form of communication [2]. On the other hand, participation in face-to-face meetings was low (50\%-70\%) and became even lower $(30 \%)$ in the case of students from the Aegean islands. In the second year of the course the number of face-to-face meetings increased from 4 to 5 , however the demand for more frequent communication was still high and the participation remained low. Furthermore, studies on dropout rates [3] reported higher rates for students who live in remote areas.

Another issue was that the study material of a course in Informatics could not be based only on textbooks. Students demanded extra material that should be available upon request. Taking into account such requirements and the experiences reported by other Universities [4] as well as examples of virtual universities [5,6], the course has gradually adopted a number of e-learning procedures, thus evolving into a mixed-model course. The following section discusses the implementation of the changes and the lessons learned during the first three years.

\section{ADOPTING E-LEARNING PROCEDURES}

The introduction of changes in the educational procedure was made gradually taking into account the available resources and the students' attitude towards the changes. Table 2 is an overview of the changes introduced since the academic year 2000-2001 including what is planned for 2003-2004. 
TABLE 2: Introducing e-learning facilities

\begin{tabular}{|c|c|c|c|c|}
\hline $\begin{array}{l}\text { Facilitie } \\
\text { s }\end{array}$ & $\begin{array}{l}0 \\
0\end{array}$ & $\begin{array}{l}0 \\
1\end{array}$ & $\begin{array}{l}0 \\
2\end{array}$ & $\begin{array}{l}0 \\
3 \\
\end{array}$ \\
\hline $\begin{array}{l}\text { Electroni } \\
\text { c } \\
\text { commun } \\
\text { ication }\end{array}$ & $\checkmark$ & & & \\
\hline $\begin{array}{l}\text { Electroni } \\
\text { C } \\
\text { delivery } \\
\text { of } \\
\text { assignm } \\
\text { ents }\end{array}$ & $\checkmark$ & & & \\
\hline $\begin{array}{l}\text { Centraliz } \\
\text { ed web } \\
\text { site }\end{array}$ & $\checkmark$ & & & \\
\hline $\begin{array}{l}\text { Special } \\
\text { web } \\
\text { sites for } \\
\text { each } \\
\text { module }\end{array}$ & & $\checkmark$ & & \\
\hline $\begin{array}{l}\text { Electroni } \\
\text { cally } \\
\text { avail. } \\
\text { study } \\
\text { material }\end{array}$ & & $\checkmark$ & & \\
\hline $\begin{array}{l}\text { Tutors' } \\
\text { forum }\end{array}$ & & $\checkmark$ & & \\
\hline $\begin{array}{l}\text { Student } \\
\text { fora for } \\
\text { module } \\
\text { groups }\end{array}$ & & $\checkmark$ & & \\
\hline $\begin{array}{l}\text { Digital } \\
\text { lectures } \\
\text { (video } \\
\text { and } \\
\text { slides) }\end{array}$ & & & $\checkmark$ & \\
\hline $\begin{array}{l}\text { Virtual } \\
\text { classroo } \\
\mathrm{m} \\
\text { meeting } \\
\mathrm{s}\end{array}$ & & & $\checkmark$ & \\
\hline $\begin{array}{l}\text { Virtual } \\
\text { laborator } \\
\text { ies }\end{array}$ & & & & $\checkmark$ \\
\hline
\end{tabular}

\subsection{Changes in the first year (2000-2001)}

During the first academic year of operation (2000-2001), emphasis was placed on assessing the effectiveness of the course and the students' opinion on it. As already mentioned, the participation rates in face-to-face meetings, the research on dropout rates and the students' opinion on the studying material indicated the need for changes. Some changes -such as increasing the number of face-to-face meetings from 4 to 5 - were implemented during this year while others are planned for the years to follow. 
Only few e-learning facilities were provided during this year since emphasis was placed on electronic communication. As a result, the initial percentage $(79 \%)$ of students who used mainly e-mail to communicate with their tutor increased to $97 \%$ towards the end of the year. Furthermore, the electronic submission of written assignments was facilitated and considered obligatory. The web site of the course remained centralized providing basic information, while the limited electronic material (programming tools, revision exercises) was distributed via e-mail by the tutors.

\subsection{Changes in the second year (2001-2002)}

During the academic year 2001-2002, the e-mail had already been established as the basic means of student-tutor communication for almost $100 \%$ of the students (including the newly registered ones). Furthermore, assignments were delivered only electronically. The central web site now offered only generic information, while specific web sites (portal-like) were provided for each module. Figure 3 shows the entry point of the module INF10 student site.

These module-specific sites included announcements, specialized electronic material (for example visualization of a sorting algorithm, computer based exercises, answers to the assignments, compilers, etc.), as well as links to students' fora, links to other sites offering valuable study material, links to other universities, etc. An example of how such material is presented is shown in Figure 4.

Although the students' response to the above changes was enthusiastic, a few educational problems occurred. Making a variety of additional material available to students created the need for providing further guidance to each student about selecting the material that suits his/her particular needs best.

This caused a slight change in the tutor's role who now undertook a more consulting role, having to aid the students in managing their time and selecting the appropriate material.

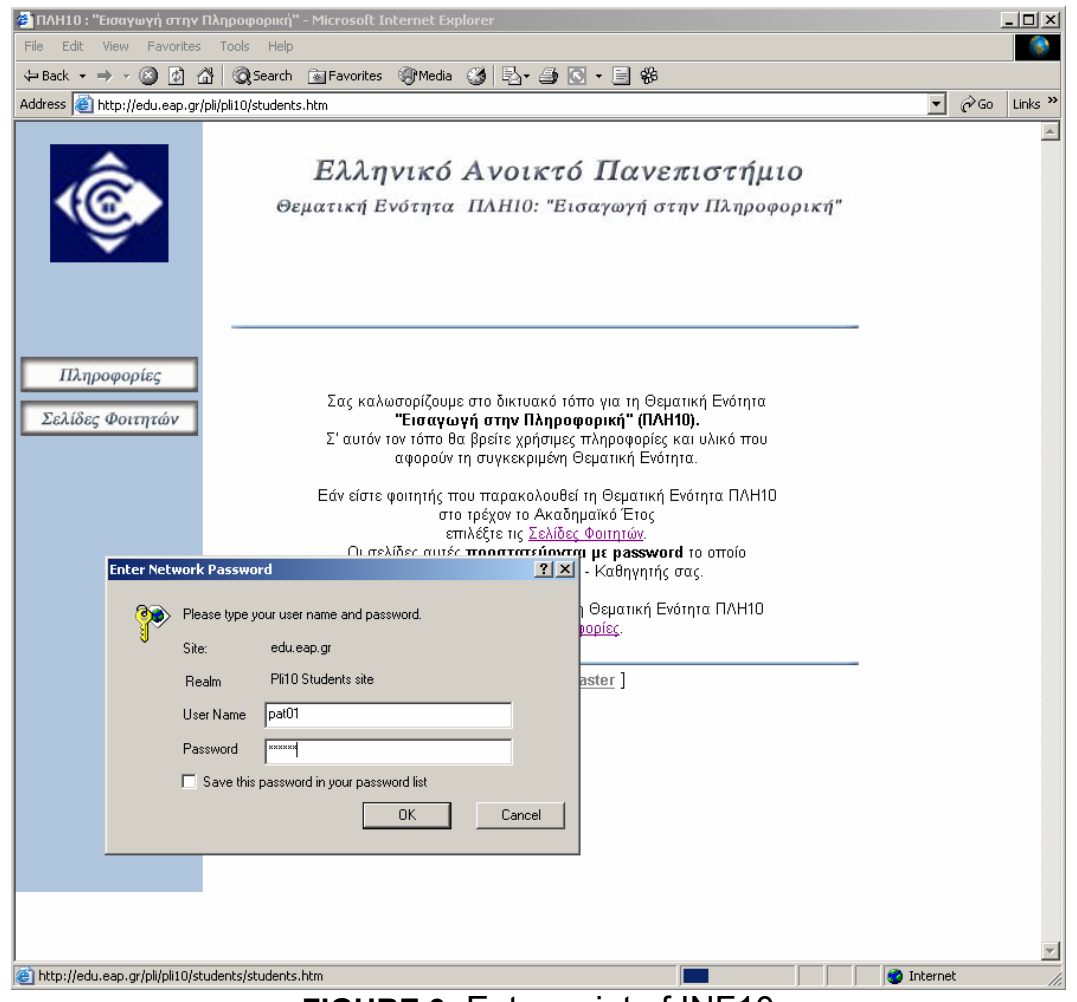

FIGURE 3: Entry point of INF10 
The tutors' forum proved to be valuable in coordinating this consulting effort, while students' fora were developed for specific module groups. Although the majority of students were in favor of using a forum (approximately $75 \%$ ), the students' fora were not all successful. The success of a forum proved to be strongly related to group specificities and the tutor-student preferred communication style. In many cases the use of e-mail and the provision of a group-specific web site including an announcement board was more effective than the forum. In Figure 5 an extract from a typical discussion in a forum of 25 first year students is shown. This is an example of an active forum with approximately 30 postings per week.

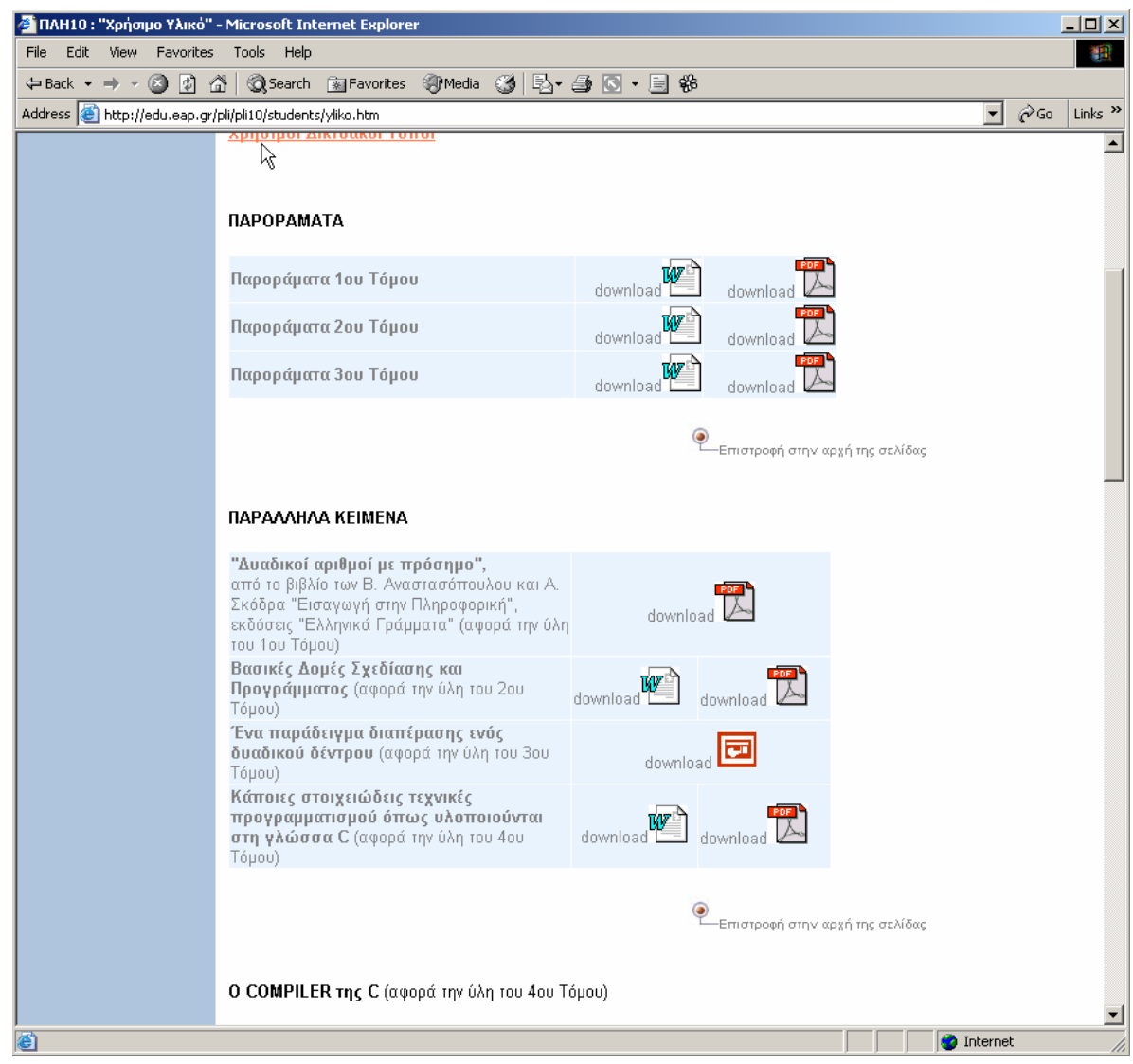

FIGURE 4: Electronic material and links

\subsection{Changes in the third year $(2002-2003)$}

During the current academic year 2002-2003, each tutor-students group uses either a forum, or a group specific web site and e-mail for communicating, depending on the specific group needs and the module. During this year an important step was taken towards e-learning by setting up student groups such as the A14 group in INF10. This group comprises 32 students, geographically distributed as shown in Figure 2. The first meeting of this group was held in Athens, while all the rest were held in a virtual classroom. In the latter case the students had the opportunity to join the virtual classroom and attend the meeting from their island. All meetings were recorded and made available through the group's web site so that the students can review them later, or be briefed on what was discussed in case they had not joined the meeting. Figure 6 shows a student (in the upper left corner area) while asking a question. This was recorded 
during the first meeting, while the tutor was explaining the use of the virtual classrooms and the communication procedure.

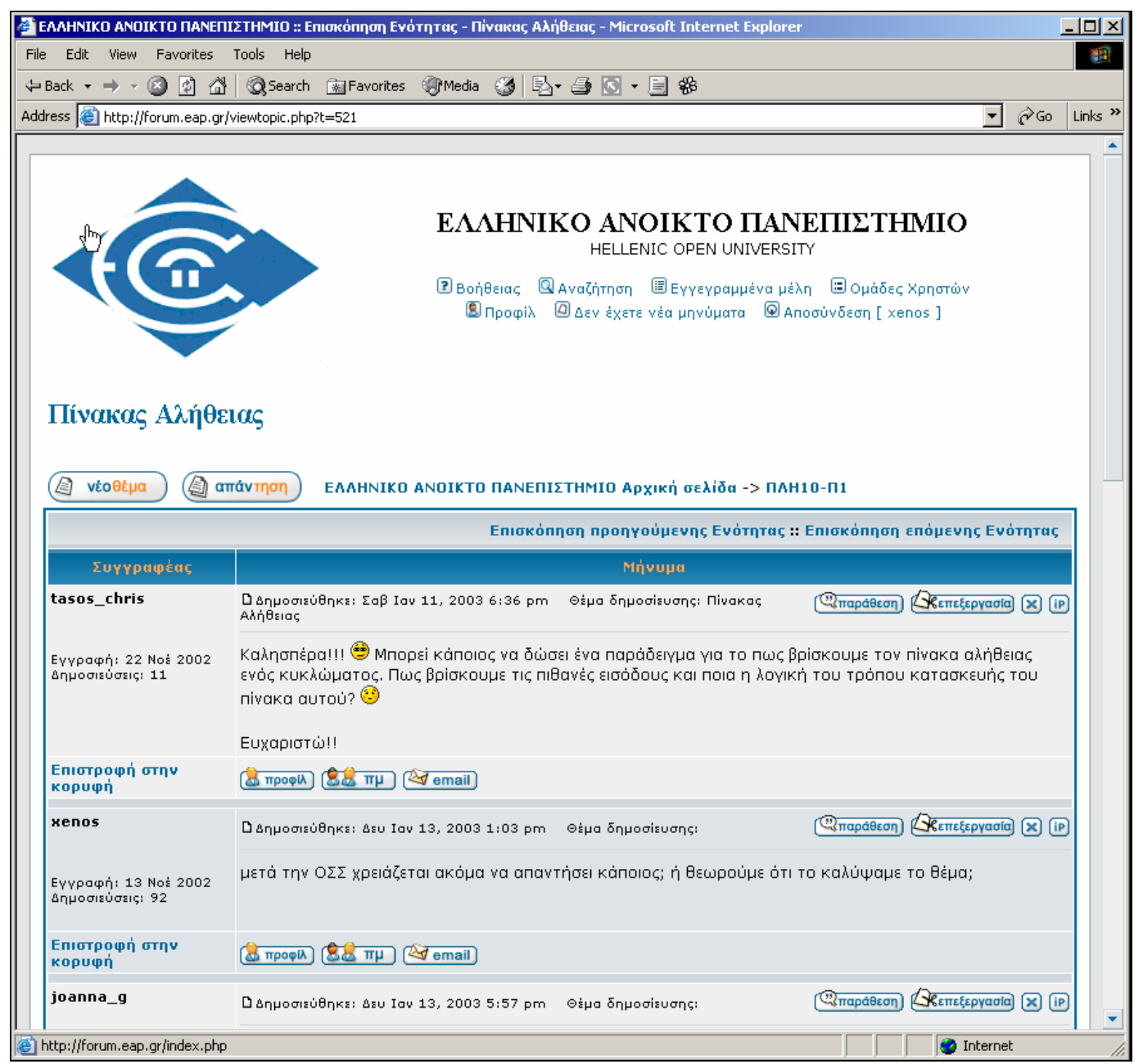

FIGURE 5: Discussion in a students' forum

The use of virtual classrooms leads to a major increase (up to $46 \%$ ) in the participation of remote students in meetings, but also caused some problems. It was shown that the virtual classrooms cannot fully substitute the students' feeling of participating in an actual classroom. On the other hand, it is definitely better to be able to participate in a virtual classroom than not participating at all, when actual meeting locations are out of reach. Another problem reported is that virtual meetings cannot follow a traditional meeting schedule. It is better to hold shorter but more frequent virtual classroom meetings than few long ones, as in the case of face-to-face meetings. It was decided to expand the use of virtual classrooms to more groups so as to further investigate their appropriateness for the educational process of the particular course.

Finally, during the current academic year digital lectures in the form of video and slides were provided through each module's web site. Material that facilitates the use of tools such as the C programming environment, written in the form of step-by-step laboratory exercises, was developed and uploaded to the module's sites. The effectiveness of digital lectures and virtual classrooms is still under review.

\subsection{Planning ahead: the use of GRID infrastructure}


Plans for the academic year 2003-2004 include the operation of a students' portal (development has already began in 2002). This portal will offer personalized access to each student and will automate further the educational process (submission of assignments, grade monitoring, etc.). A digital library of available lectures is also under development, while special rooms will be provided for recording lectures and virtual meetings. The success of virtual meetings during the current academic year (2002-2003) may change the way all meetings are organized. As already noted in the previous section, a schema with fewer long face-to-face meetings and many short virtual classroom meetings seems more effective at the time. Another future goal is to set up virtual laboratories.

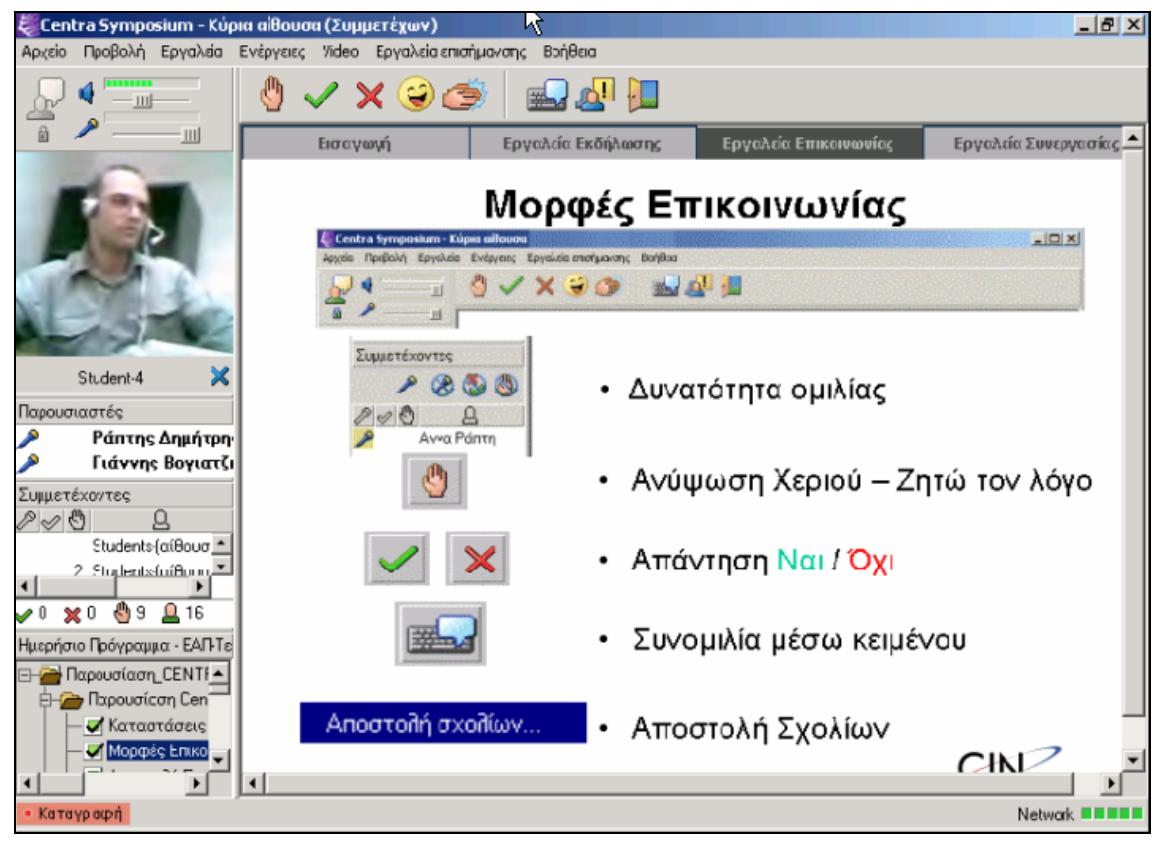

FIGURE 6: A student during a virtual classroom meeting

All aforementioned future goals must take into account that e-learning is not an electronic variant of traditional education [7], since many cultural and human aspects (as previously discussed) must be considered. GRID technologies can help to overcome difficulties relating to such aspects by improving the e-learning facilities and offering to students the feel that they participate in a real university environment. GRID technologies can also provide a networkbased computing infrastructure offering security, resource access, information and other services. Such services can help towards improving virtual classrooms by enhancing them with the use of interactive multimedia objects, offering advanced facilities promoting collaborative learning and implementing virtual laboratories. GRID infrastructure is an important step towards an e-university including e-learning, e-administration and e-research communities.

\section{CONCLUSIONS}

Problems are likely to occur in every attempt to change an educational model. In the case of the course of Informatics in the Hellenic Open University, the evolution from a traditional distancelearning model to an e-learning model was not the goal. The main objective was the constant improvement of the education quality and in certain cases improvement cannot be achieved without the use of current technology and the exploitation of e-learning infrastructures. At the current phase the course of Informatics operates based on a mixed-model that seems to constantly evolve towards e-learning. The careful introduction of e-learning facilities in the course's educational procedure can aid in overcoming major problems such as the limited 
participation in face-to-face meetings, the constant demand for updated material available even daily, and the high dropout rates of geographically remote areas.

In the case presented in this paper, a number of e-learning facilities were gradually introduced in a distance-learning course. There is still a lot of work to be done in this direction, but modern technologies are here to aid us. GRID infrastructure is among them.

\section{REFERENCES}

[1] UK Open Universy, Web site: http://www.open.ac.uk/

[2] Pierrakeas C., Xenos M., Pintelas P. (2001) Evaluating material and tutors. Students opinions and points for improvement (Paper in Greek). 1st Panhellenic Conference in Open and Distance Education, Patras.

[3] Xenos M., Pierrakeas C., Pintelas P., (2002) A Survey on Student Dropout Rates and Dropout Causes Concerning the Students in the Course of Informatics of the Hellenic Open University. International Journal of Computers \& Education, Vol. 39 (4), pp. 361-377.

[4] Trindade, A. R., Carmo, H., Bidarra, J. (2000) Current Developments and Best Practice in Open and Distance Learning. International Review of Research in Open and Distance Learning, 1 (1).

[5] Universitat Oberta de Catalunya (UOC). Web site: http://www.uoc.es

[6] University of Southern Queensland, Web site: http://www.usqonline.com.au

[7] Gerri S., (2002). Human and Artificial Agent's Conversations on the GRID", 1st Int. LeGEWG Workshop, Lausanne. 